\title{
Intention Versus Reality: Family Medicine Residency Graduates' Intention to Practice Obstetrics
}

\author{
Tyler W. Barreto, MD, Aimee R. Eden, PhD, MPH, Stephen Petterson, PhD, \\ Andrew W. Bazemore, MD, and Lars E. Peterson, MD, PhD
}

Although $21 \%$ of new family medicine graduates in 2016 reported an intention to include obstetric delivery in their scope of practice, only $7 \%$ of family physicians currently do so. The reasons for this stark difference must be identified in order to address potential barriers leading to family medicine graduates ultimately not including obstetric delivery despite intent. (J Am Board Fam Med 2017;30: 405-406.)

Keywords: Family Physicians, Obstetrics, Pregnancy

Previous studies have shown a decrease in the number of family physicians including obstetric delivery in their scope of practice. ${ }^{1-3}$ A study of 2014 data showed a much higher percentage of graduating family medicine residents intending to perform deliveries compared with those actually doing so. ${ }^{2}$ With a projected shortage of obstetricians/gynecologists and the continued decline in family physicians including delivery as a part of their practice, those new family medicine graduates who want to include deliveries are urgently needed to do so. ${ }^{4}$

To determine whether the discrepancy between intention and current inclusion of delivery in practice has continued, we used data from the American Board of Family Medicine's Family Medicine Certification examination application questionnaire, completed by both graduating residents and practicing physicians, from 2014 to 2016. Physicians complete the questionnaire, which is a required

This article was externally peer reviewed.

Submitted 10 March 2017; revised 29 March 2017; accepted 4 April 2017.

From the Robert Graham Center, Washington, DC (TWB, SP, AWB); and American Board of Family Medicine, Lexington, KY (ARE, LEP).

Funding: none.

Conflict of interest: Drs. Eden and Peterson are employees of the ABFM.

Corresponding author: Tyler W. Barreto, MD, Robert Graham Center, 1133 Connecticut Ave NW \#1100, Washington, DC 20036 (E-mail: barretotw@gmail.com). component of the examination application, on average 3 months before the examination. We compared the intentions of graduating residents to include delivery with reported provision of deliveries by practicing family physicians.

From 2014 to $2016,23 \%$ of new graduates intended to perform deliveries, whereas fewer than $10 \%$ of practicing family physicians performed deliveries (Figure 1). The difference between the percentage of new graduates intending to deliver and current family physicians actually including delivery persists even when comparing new graduates (23\%) with family physicians recertifying for the first time (9\%).

We found a persistent gap between the percentage of family medicine residents intending to perform deliveries and the percentage of practicing family physicians currently performing deliveries, which warrants further investigation. If barriers that prevent family physicians from including obstetric delivery in their scope of practice-such as malpractice, challenges obtaining hospital privileges, lifestyle concerns, hospital closures, and volume issues-are not addressed with policy and training interventions, this component of the family physician's scope of practice may disappear.

To see this article online, please go to: bttp://jabfm.org/content/ 30/4/405.full. 
Figure 1. Percentage of third-year family medicine residents intending to perform obstetric delivery $(\mathrm{n}=9128)$ and percentage of practicing family physicians performing obstetric deliveries, by testing cohort: first recertification $(n=8059)$, second recertification $(n=7186)$, $\geq$ third recertification $(n=10,589)$. Data are the means from 2014 to 2016.

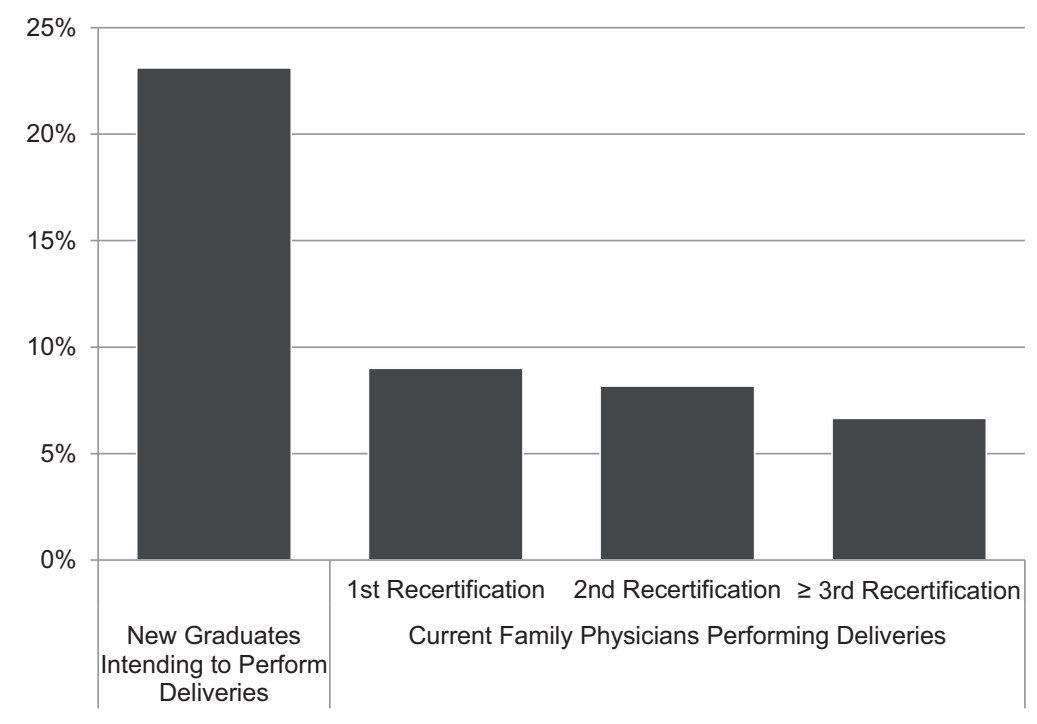

\section{References}

1. Rayburn WF, Petterson SM, Phillips RL. Trends in family physicians performing deliveries, 2003-2010. Birth 2014;41:26-32.

2. Coutinho AJ, Cochrane A, Stelter K, Phillips RL, Peterson LE. Comparison of intended scope of practice for family medicine residents with reported scope of practice among practicing family physicians. JAMA 2015;314:2364-72.
3. Tong STC, Makaroff LA, Xierali IM, et al. Proportion of family physicians providing maternity care continues to decline. J Am Board Fam Med 2012;25: $270-1$.

4. American College of Obstetricians and Gynecologists. The obstetrician gynecologist workforce in the United States: facts, figures, and implications 2011. Washington, DC: ACOG Distribution Center; 2011. 